\title{
Impact of climate change on the groundwater sustainability in the lower Chao Phraya basin, Thailand
}

\author{
Pinit Tanachaichoksirikun ${ }^{1, *}$, Uma Seeboonruang ${ }^{2}$, and Phayom Saraphirom ${ }^{3}$ \\ ${ }^{1}$ PhD. Student, Civil Engineering Department, Faculty of Engineering, King Mongkut's Institute of Technology Ladkrabang, \\ Bangkok, Thailand \\ 2 Associate Professor, Civil Engineering Department, Faculty of Engineering, King Mongkut's Institute of Technology Ladkrabang, \\ Bangkok, Thailand \\ ${ }^{3}$ Lecturer, Agricultural Engineering Department, Faculty of Engineering, Khon Kean University, Thailand
}

\begin{abstract}
This research investigates the impact of climate change on the hydraulic heads of Thailand's Lower Chao Phraya basin. The research also determines the sustainability of groundwater as the result from climate change. In the study, the climatic scenario (IPSL-CM5A-MR) of the Representative Concentration Pathways (RCP) between 2.6, 4.5 and 8.5 were considered, and the simulations were carried out using the three-dimensional groundwater flow model (i.e. MODFLOW-2000) predicting the groundwater behavior between 2017 and 2036. The findings revealed that the impact of climate change on the hydraulic head fluctuation was positively correlated. Specifically, under the IPSL-CM5A-MR RCP 4.5 that has the highest average precipitation, the average hydraulic head increased. In conclusion, the sustainability of groundwater in the Lower Chao Phraya basin was sufficient during the simulated time. However, the groundwater budget was lower than the average groundwater budget during $2009-2014$ indicating, the groundwater storage was continuously decreased. Specifically, the $2^{\text {nd }}$, and $3^{\text {rd }}$ (Phra Pradeang and Nakorn Luang) aquifers may be facing the groundwater shortage in the future.
\end{abstract}

\section{Introduction}

Groundwater is an important resource and a secondary source of water when facing critical droughts and disasters. In addition, climate change is probably one of the most challenging pressures facing hydrological systems and water resources. Consequently, there are several researches subject to the effect of climate change on the groundwater resource such as [1], [2], [3], [4], [5], [6]. [2] investigated the impact of climate change on two small aquifers in western Canada and the United States and revealed the impact from climate change on recharge and groundwater levels at both study areas. In addition, [1] examined the impact of climate change on a chalky groundwater basin in Belgium and showed two models had the groundwater levels decreased, while the other showed no significantly changed. Moreover, [7] carried out the study of climate change on groundwater levels in Lansing, Michigan and found that the simulated steadystate groundwater levels were generally predicted to increase or decrease depending on climate change scenarios.

Recent research investigated the effect of climate change on the groundwater In Thailand, for example, [4] performed climate change and groundwater resources in Thailand and explained the climate change effect on the groundwater quality and quantity and the groundwater policy. Moreover, [8] determined impact of climate change on groundwater and vulnerability to drought of areas in eastern Thailand and reported the risky hotspots and prioritized zones threatened by persistent droughts. In addition, [9] applied an empirical decomposition to study deep groundwater and possible link to climate variability in the Lower Chao Phraya basin and revealed that the groundwater significantly related to the groundwater withdraw than the climate variability.

Even though, there are several studies that focus on the impact of climate change on the groundwater resource, little research focused on the groundwater sustainability. Thus, this study aims to predict the impact of climate change on the hydraulic head in the Lower Chao Phraya (LCP) basin, Thailand by using numerical simulations. In addition, the groundwater sustainability was determined by two variables: groundwater recharge and groundwater demand.

\section{Study area}

\subsection{General and topography}

Fig. 1 illustrates the Lower Chao Phraya (LCP) basin, Thailand. The area covers $43,317 \mathrm{~km}^{2}, 21$ provinces including Bangkok, which is the capital city. The LCP basin located in the central Thailand. The western part is the Tenasserim hills range, and the northern part is a small hill which separates the Upper Chao Phraya basin. The southern part connects to the Gulf of Thailand. The basin has slope from the north to the south. The LCP

\footnotetext{
* Corresponding author: 57601070@kmitl.ac.th
} 
basin contains four constituent rivers (i.e. the Chao Phraya, Mae Klong, Pa Sak and Tha Chin rivers).

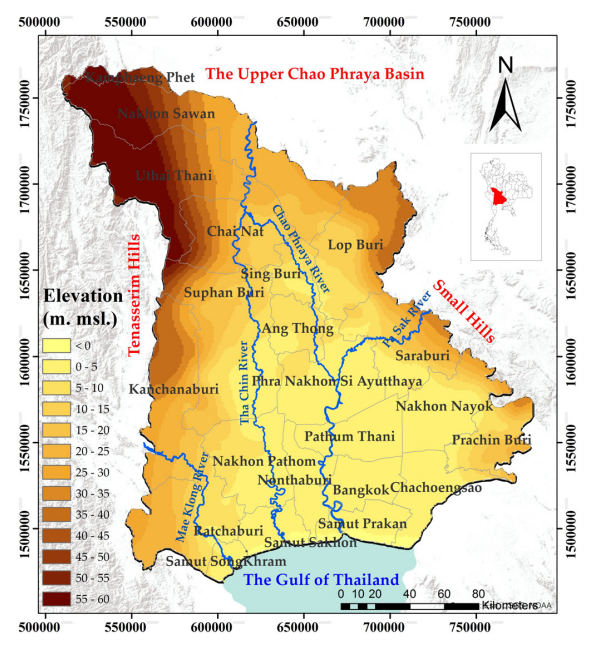

Fig. 1 The geographical map of the Lower Chao Phraya basin 2.2 Hydrogeology

The hydrogeology of the LCP basin is the groundwater in unconsolidated materials and accounts for the largest proportion of groundwater in the basin [10]. In addition, sediments in the basin are predominantly of old floodplain deposits aquifer. The LCP basin has eight aquifer layers, which are Bangkok (BK $\sim 50 \mathrm{~m}$ ), Phra Pradeang (PD 100 m), Nakorn Luang (NL 150 m), Nonthaburi (NB $\sim 200 \mathrm{~m}$ ), Sam Khok (SK $250 \mathrm{~m}$ ), Phayathai (PT $\sim 300 \mathrm{~m}$ ), Thonburi (TB $\sim 350 \mathrm{~m}$ ) and Pak Nam (PN $\sim 400 \mathrm{~m}$ ) aquifers.

\section{Methodology}

\subsection{Model design and boundary conditions}

In this research, the LCP basin was divided into nine layers, consisting of the eight aquifers and the top layer was Bangkok clay (BKC).

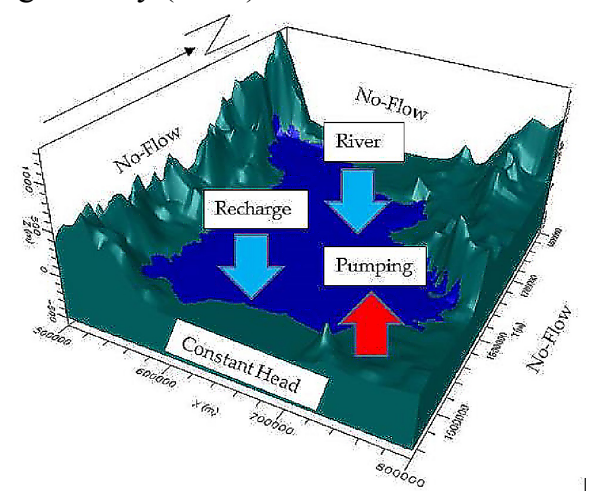

Fig. 2 The 3D model of the LCP basin and the boundaries

Fig.2 illustrated the three-dimensional model of groundwater and the boundaries in the LCP basin. The model composes of nine layers which individually discretized into $350 \times 300$ (row x column) grid sizes of $1 \mathrm{x} 1 \mathrm{~km}^{2}$ each to efficiently determine the hydraulic heads. The model generation was carried out using MODFLOW-2000 [11]. The underside was treated as a no-flow boundary of impermeable bedrock; the west side as other no-flow boundary of the Tenasserim hills range; and the north as another no-flow boundary of the small hills separating the upper and lower Chao Phraya basins. The four constituent rivers (the Chao Phraya,
Mae Klong, Pa Sak and Tha Chin rivers) were treated as the river boundary, which was constantly gaining and losing between the surface water and groundwater. On the south side, the interface between the aquifers layers and the Gulf of Thailand were treated as the constant-head boundary, where the groundwaterseawater connected. The top of the model was treated as the recharge boundary from the rainfall. The aquifers in the LCP basin were pumped for consumption, agriculture and industry.

\subsection{Transient calibration and validation}

Fig. 3(a) illustrated the calibration of the groundwater model, which was performed during the period $2009-$ 2014 based on 271 observation wells. The groundwater levels were compared to the actual groundwater levels. The results of the transient calibrated model reveal absolute residual mean of $1.74 \mathrm{~m}$ and root mean squared (RMS) error of $2.35 \mathrm{~m}$ with normalized RMS of $2.38 \%$.

Fig. 3(b) showed the validation of the groundwater model, which was analyzed between 2007 and 2008 based on 235 observation wells. The results of the validated model show the absolute residual mean of $1.58 \mathrm{~m}$ and root mean squared (RMS) error of $2.15 \mathrm{~m}$ with normalized RMS of $2.16 \%$.

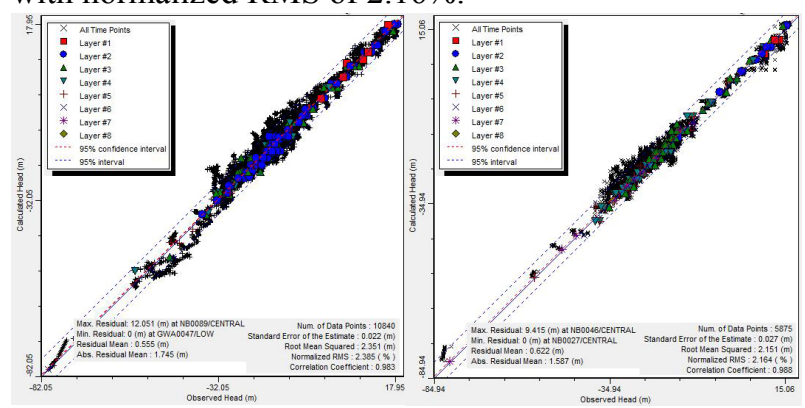

Fig. 3 The relationship between simulated and observed hydraulic head (a) calibrated model (b) validated model 3.3 Selected and simulated climate scenarios The climatic model was selected and prepared by [12] and the model was conducted based on six criteria (i.e., average temperature, annual rainfall, humidity, pressure, evaporation and water discharge). IPSL-CM5A-MR (The Institute Pierre Simon Laplace) which is the one of climatic scenarios of the Coupled Model International research group (CMIP5) was selected, giving preference to scenarios offering the minimum bias and root mean square error on the annual precipitation in the Chao Phraya watershed [13]. Moreover, the Representative Concentration Pathways (RCP) 2.6, 4.5 and 8.5 were chosen to give the most contrasted climate changes.

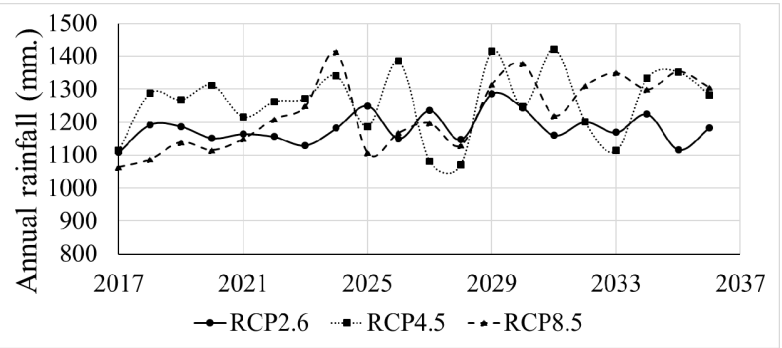

Fig. 4 Annual rainfall of the IPSL-CM5A-MR was varied the RCP 2.6, 4.5 and 8.5 during period $2017-2036$

Fig. 4 illustrated the annual rainfall of the climatic scenarios of RCP 2.6, 4.5 and 8.5 during period 2017 - 
2036. The average annual rainfall under RCP 2.6, 4.5 and 8.5 were $1,182,1,258$ and $1,227 \mathrm{~mm}$, respectively, while the trend of the annual rainfall increased by 1.85 , 2.64 and $12.78 \mathrm{~mm}$, respectively.

\subsection{Simulation scenarios}

In the model, the period during 2009 - 2014 was used as the base case to determine the impact of climate change on the hydraulic head in the LCP basin. In addition, the research investigated the sustainability of groundwater in the specific basin. In the climatic scenario of RCP 2.6, 4.5 and 8.5 , monthly precipitation was generated in the future between 2017 and 2036. The assessment was carried out with regard to the impact of climate change on the hydraulic head and the sustainability of groundwater in the area-specific.

\section{Results and discussion}

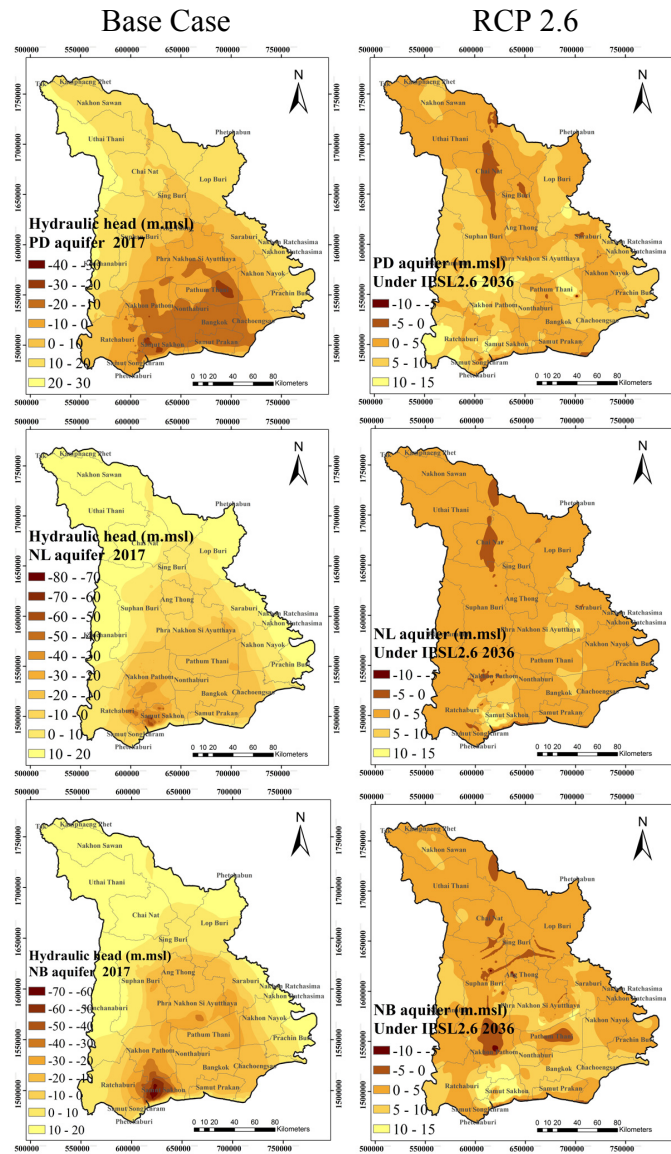

\subsection{Impact of climate change on the hydraulic heads}

Figs.5 illustrated the simulated hydraulic head fluctuation associated with the PD, NL and NB aquifers under the base case (2009-2014) and IPSL-CM5A-MR with the variable RCPs (2.6, 4.5 and 8.5). In RCP 2.6 during the period $2017-2036$, the average hydraulic head in PD, NL and NB increased by 4.94, 4.70 and $3.93 \mathrm{~m}$, respectively vis-à-vis the base case, under RCP 4.5 the average hydraulic head in PD, NL and NB increased by $5.23,4.87$ and $4.03 \mathrm{~m}$, respectively vis-àvis the base case, under RCP 8.5 the average hydraulic head in PD, NL and NB increased by 5.09, 4.76 and $3.96 \mathrm{~m}$, respectively vis-à-vis the base case. Essentially, the high precipitation gives rise to the hydraulic head increase.

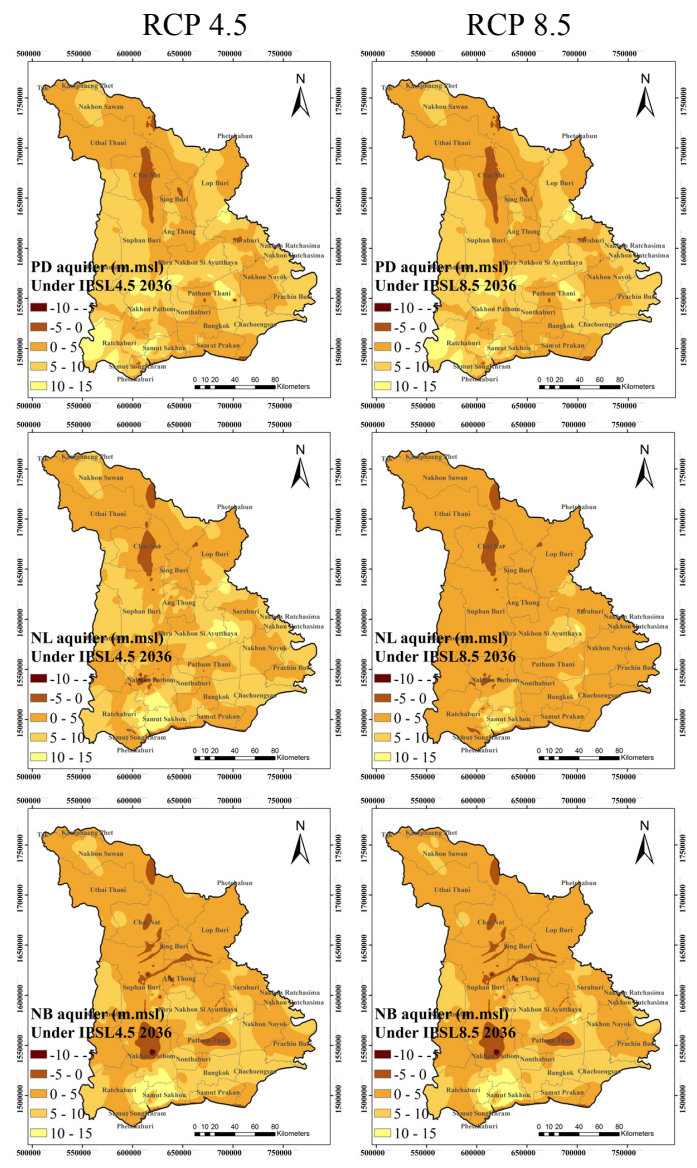

Fig. 5 The simulated hydraulic head in the PD, NL and NB aquifers under the base case and IPSL-CM5A-MR with RCP 2.6, 4.5 and 8.5 between the period 2017-2036

\subsection{Sustainability of groundwater}

Figs. 6(a-c) respectively illustrated groundwater budget in dry and rainy season and groundwater demand in the PD, NL and NB aquifers under IPSL-CM5A-MR RCP of 2.6, 4.5 and 8.5. The influence of seasonal fluctuates in PD aquifer was shown in Fig. 6(a). Under RCP 2.6, the average rate of groundwater budget in dry and rainy season were 1.65 and 2.11 million $\mathrm{m}^{3} /$ day, respectively. Under RCP 4.5, the average rate of groundwater budget in dry and rainy season were 1.76 and 2.29 million $\mathrm{m}^{3} /$ day, respectively. Under $\mathrm{RCP} 8.5$, the average rate of groundwater budget in dry and rainy season were 1.71 and 2.19 million $\mathrm{m}^{3} /$ day, respectively. While the average groundwater demand is 0.30 million $\mathrm{m} 3 /$ day and the rate of groundwater demand continuously increased by $20 \mathrm{~m}^{3} /$ day. Fig. 6(b), under RCP 2.6, the average rate of groundwater budget in dry and rainy season were 1.24 and 1.27 million $\mathrm{m}^{3} /$ day, respectively. Under RCP 4.5, the average rate of groundwater budget in dry and rainy season were 1.30 and 1.33 million $\mathrm{m}^{3} /$ day, respectively. Under RCP 8.5 , the average rate of groundwater budget in dry and rainy season were 1.26 and 1.30 million $\mathrm{m}^{3} /$ day, respectively. While the average groundwater demand is 0.1 million $\mathrm{m}^{3} /$ day and the rate of groundwater demand continuously increased by $9 \mathrm{~m}^{3} /$ day. Fig. 6(c), under RCP 2.6, the average rate of groundwater budget in dry and rainy season were 1.12 and 1.10 million $\mathrm{m}^{3} /$ day, respectively. Under RCP 
4.5 , the average rate of groundwater budget in dry and rainy season were 1.16 and 1.15 million $\mathrm{m}^{3} /$ day, respectively. Under RCP 8.5 , the average rate of groundwater budget in dry and rainy season were 1.13 and 1.12 million $\mathrm{m}^{3} /$ day, respectively. While the average groundwater demand is 0.05 million $\mathrm{m}^{3} /$ day and the rate of groundwater demand continuously increased by $1 \mathrm{~m}^{3} /$ day. The high precipitation rendered the great groundwater recharge then the higher groundwater is stored.
The groundwater budget during period 2017 - 2036 was greater than the groundwater extraction. Consequently, the sustainability of groundwater in the LCP basin was sufficient. However, the groundwater budget was lower than the average groundwater budget during period 2009 - 2014 (baseline) that means groundwater storage continuously decreased. Therefore, $\mathrm{PD}$ and NL aquifers may be facing the groundwater shortage in the future.

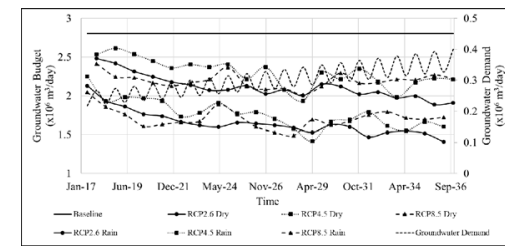

(a)

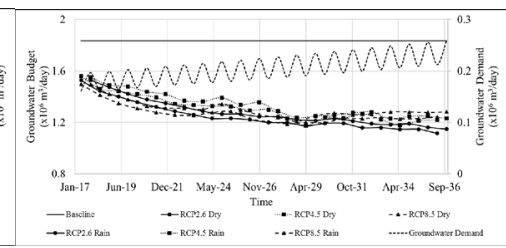

(b)

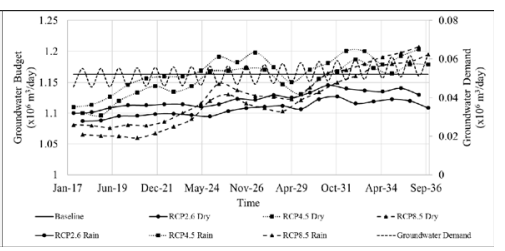

(c)

Fig. 6 The rate of groundwater budget and groundwater demand in dry and rainy season (a) PD, (b) NL, (c) NB aquifers

\section{Conclusions}

This research has investigated the impact of variable climate on the hydraulic head in Thailand's Lower Chao Phraya (LCP) basin, and the sustainability of groundwater in the area-specific. In the study, the period during 2009 - 2014 was used as the base case. Using the climatic scenario (IPSL-CM5A-MR) was varied between RCP 2.6, 4.5 and 8.5 during periods 2017 and 2036. The simulations were carried out using MODFLOW-2000. The findings revealed that the impact of climate change on the hydraulic head fluctuation was positively correlated. Specifically, the simulation under IPSL-CM5A-MR RCP 4.5 that had the highest average precipitation resulted in the greatest average hydraulic head increase. In addition, the sustainability of groundwater of the Lower Chao Phraya (LCP) basin was obtained during period 2017 - 2036 . However, the groundwater budget was lower than the average groundwater budget during 2009 - 2014 indicating, the groundwater storage was continuously decreased. Specifically, PD and NL aquifers may be facing the groundwater shortage in the future.

\section{Acknowledgements}

The authors would like to extend deep gratitude to the Thailand Research Fund through the Royal Golden Jubilee PhD Program (Grant No. PHD/0189/2556) for the financial sponsorship. Sincere appreciation goes to the Land Development Department, the Thai Meteorological Department and the Thailand Department of Groundwater Resources for the data.

\section{References}

1. S. Brouyère, G. Carabin, A. Dassargues. Climate change impacts on groundwater resources: modelled deficits in a chalky aquifer, Geer basin, Belgium. Hydrogeol. J., 12, 123-134 (2004)

2. D. M. Allen, D. C. Mackie, M. Wei. Groundwater and climate change: a sensitivity analysis for the Grand Forks aquifer, southern British Columbia, Canada. Hydrogeol. J., 12, 270-290 (2004)

3. M. I. Jyrkama, J. F. Sykes. The impact of climate change on spatially varying groundwater recharge in the Grand River watershed (Ontario). J. Hydrol., 338, 237-250 (2007)

4. K. Srisuk, T. Nettasana. Climate change and groundwater resources in Thailand. $J$. Gw. Sc. and E., 5, 67-75 (2016)

5. F. Bouraoui, G. Vachaud, L. Z. X. Li, H. Le Treut, T. Chen. Evaluation of the impact of climate changes on water storage and groundwater recharge at the watershed scale. Clim. Dyn., 15, 153-161 (1999)

6. S. T. Woldeamlak, O. Batelaan, F. De Smedt. Effects of climate change on the groundwater system in the Grote-Nete catchment, Belgium. Hydrogeol. J., 15, 891-901 (2007)

7. T. E. Croley, C. L. Luukkonen. Potential effects of climate change on ground water in Lansing, Michigan. JAWRA, 39, 149-163 (2003)

8. U. Seeboonruang. Impact assessment of climate change on groundwater and vulnerability to drought of areas in Eastern Thailand. Envir. Earth Sc., 75, 42 (2016)

9. U. Seeboonruang. An empirical decomposition of deep groundwater time series and possible link to climate variability. GNEST J., 16, 87-103 (2014)

10. Thailand Department of Groundwater Resources Groundwater situation, Thailand 2015 Quarter 1, Ministry of Natural Resources and Environment, Bangkok. (2015) (in Thai)

11. A. W. Harbaugh, E. R. Banta, M. C. Hill, M. G. McDonald. MODFLOW-2000, The U. S. Geological Survey Modular Ground-Water ModelUser Guide to Modularization Concepts and the Ground-Water Flow Process, Open-file Report. USGS 92, 134 (2000)

12. J. Wattanasetpong, P. Charoenvaravut, W. Laosinwattana. Downscaling climate models in Thailand by artificial neural network method. Thesis of civil engineering, King Mongkut's Institute of Technology Ladkrabang, Bangkok, Thailand. (2015) (in Thai)

13. P. Ruangrassamee, A. Khamkong, P. Chuenchum. Assessment of precipitation simulations from CMIP5 climate models in Thailand. ICWRE3, 591599 (2015) 